\title{
Application of Mechanical Vapor Recompression to Acetone - Methanol Separation
}

\author{
Le Cao Nhien, Gyeongmin Kim, Riezqa Andika, Yuli Amalia Husnil, and Moonyong Lee
}

\begin{abstract}
This paper proposed a novel integrated design of azeotropic mixtures distillation process based on mechanical vapor recompression (MVR). The extractive distillation of acetone - methanol binary system that forms a homogeneous minimum - boiling azeotrope was studied. Based on the simulation result, the total energy consumption of the proposed sequence is $62 \%$ less than the existing extractive distillation configuration.
\end{abstract}

Index Terms-Mechanical vapor recompression, MVR, heat integration, azeotropic distillation, extractive distillation.

\section{INTRODUCTION}

In recent years, separation by distillation columns is the primary technology in chemical processing industries. It is commonly known in chemical industry world that distillation process is ranked in a third of the total used energy in chemical industry [1]. Non-ideal and azeotropic mixtures are mostly encountered in chemical industries. Many academic research have been conducted to investigate the azeotropic distillation process especially on finding a good approach to decrease the energy consumption to separate the respective mixtures [2], [3].

Because these mixtures are impossible to separate using a single conventional column, numerous non-conventional distillation techniques have been suggested to answer this issue [4]-[7]. The most common methods are pressure-swing distillation and extractive distillation. The first option often used in the mixtures that are very sensitive to pressure. The latter, which is the normal non-conventional distillation process used in the chemical industry is economically feasible if a suitable solvent can be found. In extractive distillation method, a nonvolatile solvent which have a high boiling point and miscible with the azeotropic mixtures is used. The different interactions between the solvent and the components of mixtures will change the relative volatility [8]. As a result, the new formed mixtures can be separated by the common distillation technologies. Particularly, for separating a binary homogeneous azeotrope, we use two-column distillation process. The feed mixture and the extractive solvent are introduced into the first column (see Fig. 1). The solvent is miscible with the feed mixture and one pure component can be obtained on the top of the first column. The second component and solvent are introduced to the second column. Due to the high boiling point of the solvent, the other component can be attained on the top of the second column,

Manuscript received December 10, 2013; revised January 22, 2014.

Moonyong Lee is with the School of Chemical Engineering, Yeungnam University, Gyeongsan 712-749, South Korea (e-mail: mynlee@ yu.ac.kr). otherwise the solvent is obtained on the bottom. Finally, the solvent is recovered to the first column after adding make-up solvent.

Extractive distillation is widely used in numerous processes, but it consumes high amount of energy, which requires dispatching [6], [9]-[14]. Process integration is an attracting choice for handling this issue and it has been successful in decreasing the energy requirements in comparison with sequences where all the units are configured with little or no integration [8]. Knapp and Doherty researched the heat integration of binary homogeneous azeotropic systems using extractive distillation methods [3]. They studied the acetonemethanol mixture with water as the solvent. They suggested the thermally-integrated sequence in which the pressure of the second column was decreased. This method was able to obtain energy saving up to $40 \%$. In another research, Luyben considered the extractive distillation in both dynamic and steady state [2]. A heat integration scheme was proposed and it was also able to attain large amount of energy saving. However, in both cases, because of increasing the pressure in the second column was increased, much of modifications were required for this column such as column diameter, tray spacing, replacement of the existing internals, etc. Moreover, these modifications require the plant to be shut leading to the product loss and the product distribution to the customers will be interrupted [15].

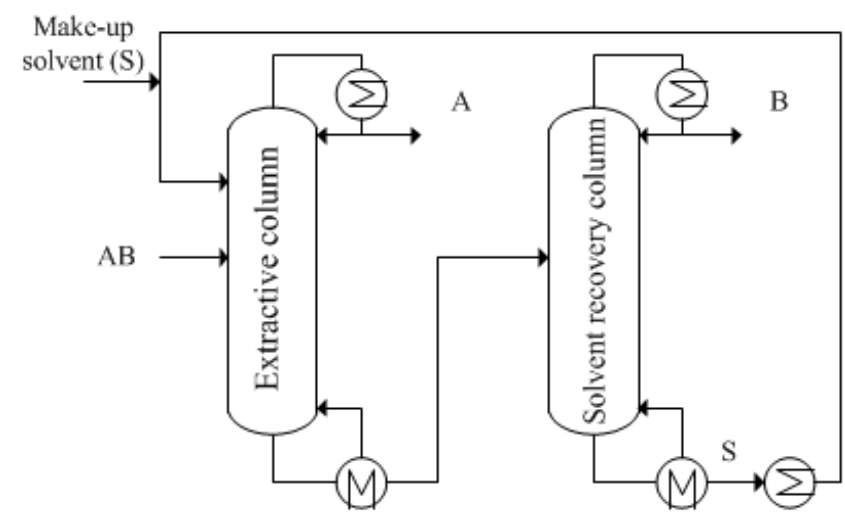

Fig. 1. Schematic diagram of conventional extractive distillation sequence.

MVR is known as a state-of-art industrial system for binary distillation and is widely applied in the separation of close boiling components [16]. According to the MVR, the top vapor is fed to the compressor and exchanging heat with the bottom stream. As the heat load is high and the temperature difference between the overhead and bottom of the column are small, this technology might be an interesting option for conserving energy [17]. However the benefit of MVR has only been studied for a single distillation column. In this 
configuration the heat of top stream is used to evaporate the bottom stream of the same column [16]-[21].

The aim of this work is to investigate an innovative integrated sequence, applying MVR for the acetone methanol system that forms a homogeneous minimum boiling azeotrope using extractive distillation sequence. The heat of the compressed overhead stream will be used to evaporate the bottom stream of the second column for conserving energy.

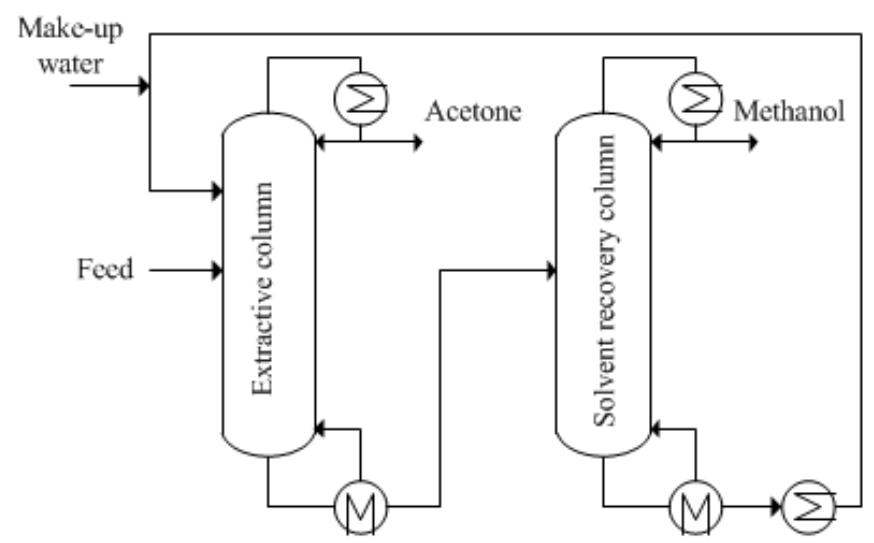

Fig. 2. Schematic diagram of the conventional extractive distillation, acetone - methanol.

\section{CONVEnTIONAL EXTRACTIVE DistiLlation}

Fig. 2 illustrates the conventional extractive distillation configuration for acetone - methanol separation. The optimal design of this mixture using the extractive solvent, water, is proposed by Knapp and Doherty [3]. The design used in this work was inspired by their research and also Luyben's work [2]. The process includes two columns, the extractive distillation column to separate acetone and the extractive solvent recovery column to separate methanol.

The Knapp - Doherty presented the optimal design which has 57-tray extractive column and a 26-tray solvent recovery column, both operating at $1 \mathrm{~atm}$ [3]. In order to produce high-purity acetone in distillate the extractive agent is fed to the extractive column on a stage above the feed stage and below the top of the column. With a feed flow rate of 540 $\mathrm{kmol} / \mathrm{h}$, a solvent flow rate must be $1,100 \mathrm{kmol} / \mathrm{h}$ to obtain the desired $95 \%$ acetone purity [2]. A cooler is also necessary to cool down the water recycle from the bottom of extractive solvent recovery column from $100{ }^{\circ} \mathrm{C}$ to $47{ }^{\circ} \mathrm{C}$ before it is recovered to the extractive column.

The acetone - methanol mixture forms a homogeneous minimum - boiling azeotrope and the third component (water) used as an extractive solvent to separate a binary mixture. A residue curve map for the acetone - methanol - water system is shown in Fig. 3. Notice that it is feasible to separate the mixture due to the fact that there is no distillation boundary dividing the composition profile into different regions.

Table I indicates the information of sequence used in this work including operating conditions, feed condition, equipment sizes, heat duties. The simulations were conducted using commercial simulation software, Aspen HYSYS V7.3. The UNIQUAC model was used to predict the thermodynamic properties.

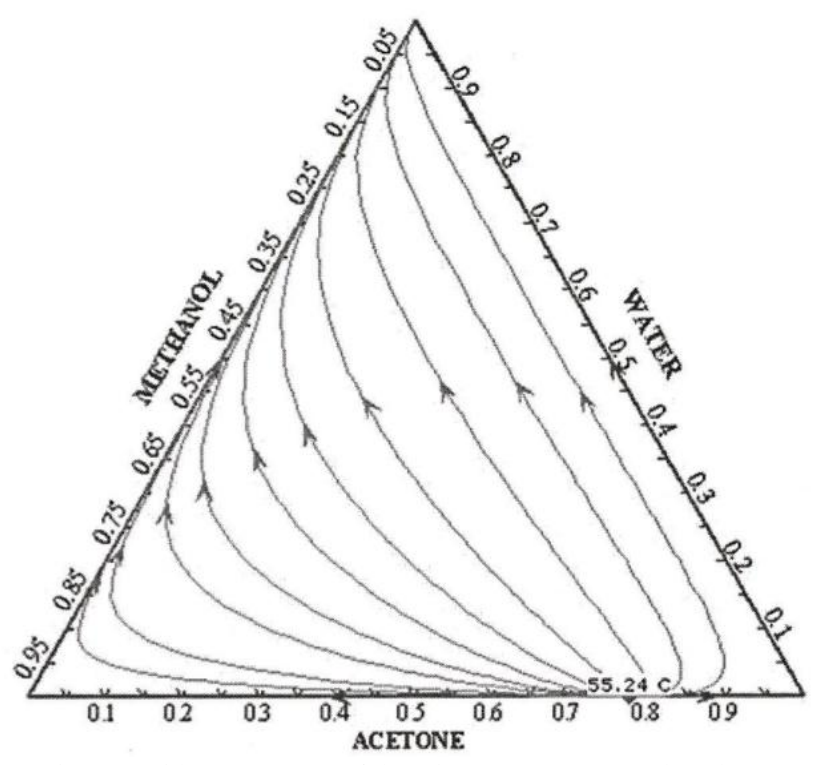

Fig. 3. Residue curve map of the mixture acetone - methanol - water.

TABLE I: PARAMETERS OF A CONVENTIONAL EXTRACTIVE DISTILLATION CONFIGURATION

\begin{tabular}{lll}
\hline Feed tray DC1 & 18 & \\
Feed tray of extractive solvent DC1 & 33 & \\
Number of trays DC1 & 57 & \\
Column diameter DC1 & 2.7 & $\mathrm{~m}$ \\
Feed tray DC2 & 12 & \\
Number of trays DC2 & 26 & \\
Column diameter DC2 & 1.7 & $\mathrm{~m}$ \\
Feed flow rate & 540 & $\mathrm{kmol} / \mathrm{h}$ \\
Feed composition (mole fraction) & $0.5 / 0.5$ & $\mathrm{acetone} / \mathrm{methanol}$ \\
Feed temperature & 47 & ${ }^{\circ} \mathrm{C}$ \\
Feed pressure & 1 & $\mathrm{~atm}$ \\
Feed flow of extractive solvent & 1100 & $\mathrm{kmol} / \mathrm{h}$ \\
Temperature of feed solvent & 47 & ${ }^{\circ} \mathrm{C}$ \\
Flow rate of make-up solvent & 1.73 & $\mathrm{kmol} / \mathrm{h}$ \\
Reboiler duty DC1 & 11300 & $\mathrm{~kW}$ \\
Reboiler duty DC2 & 6894 & $\mathrm{~kW}$ \\
Pressure DC1 & 1 & $\mathrm{~atm}$ \\
Pressure DC2 & 1 & $\mathrm{~atm}$ \\
Purity of acetone & 99.5 & $\%$ mole \\
Purity of methanol & 99.5 & $\%$ mole \\
\hline
\end{tabular}

\section{PROPOSED PROCESS CONFIGURATION BASED ON MVR}

In the studied sequence, the base temperature in the $\mathrm{DC} 1$ is $81{ }^{\circ} \mathrm{C}$, while the condenser temperature in DC1 and DC2 are $56{ }^{\circ} \mathrm{C}$ and $64{ }^{\circ} \mathrm{C}$, respectively. The small temperature difference between the two condenser temperatures with the base temperature in DC1 shows an attractive option to apply MVR for the two-column extractive distillation column.

Fig. 4 indicates the flowsheet of the integrated extractive distillation sequence. In this integrated process, stream 1 represents a feed stream of the acetone - methanol azetropic mixture and stream 2 represents an extractive solvent (water) feed stream. These streams are fed into the DC1. The vapor stream from DC1 is compressed adiabatically by a compressor $(3 \rightarrow 4)$. Next, stream 4 is cooled in a heat exchanger $(4 \rightarrow 5)$, and temperature of stream 5 are adapted by a cooler $(5 \rightarrow 6)$. The liquid stream (6) is divided into two streams (7 and 8 ). Stream 8 becomes a product stream (pure 
acetone) and stream 7 as a reflux stream to DC1. Stream 9 and stream 13 are heated in a heat exchanger and fed into DC1. Meanwhile, stream 15 is fed to the DC2. At the same time, the distillate stream from DC2 is adiabatically compressed by a compressor $(16 \rightarrow 17)$ and cooled by exchanging heat in heat exchanger $(17 \rightarrow 18)$. The temperature of stream 18 is adapted by a cooler $(18 \rightarrow 19)$, and the liquid stream $(19)$ is divided into two streams (20 and 21). Subsequently, stream 20 is fed into DC2 as the recycled stream and stream 21 is the product methanol.

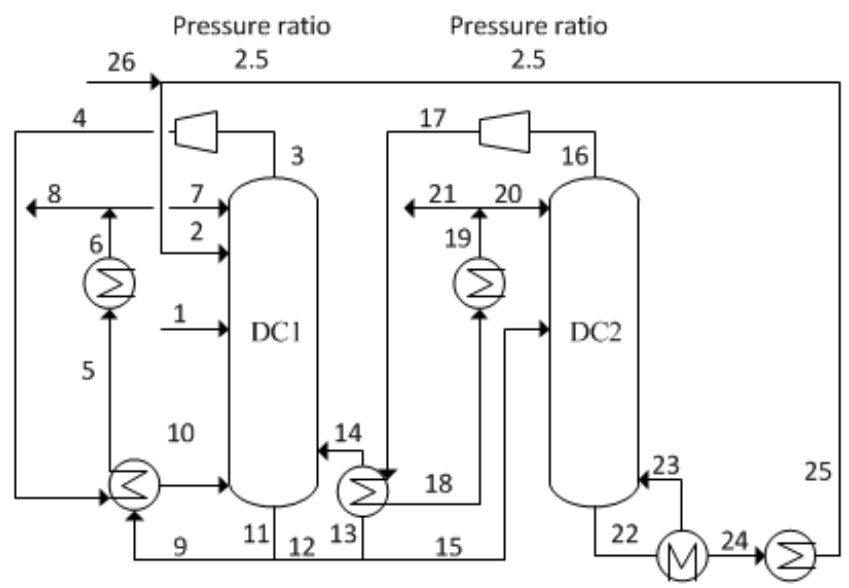

Fig. 4. Proposed extractive distillation sequence.

\section{SimUlation RESUlt AND DisCUSSION}

Considering a distillaltion sequence that separates the azeotropic mixture of acetone (50\% mole) and methanol (50\% mole) at temperature of $47{ }^{\circ} \mathrm{C}$ and operating pressure of $1 \mathrm{~atm}$, the energy consumption for the proposed sequence for the azeotropic distillation column was calculated and compared to the conventional extractive sequence (see Table II). In all heat exchangers, the minimum temperature approach was kept constant at $10{ }^{\circ} \mathrm{C}$. The adiabatic efficiency of the compressor was assumed $75 \%$.

TABLE II: SUMMARY OF RELATIVE PERFORMANCE FOR AZEOTROPIC DISTILLATION

\begin{tabular}{lcc}
\hline \hline & $\begin{array}{c}\text { Conventiona } \\
\text { l sequence }\end{array}$ & $\begin{array}{c}\text { Integrated } \\
\text { sequence }\end{array}$ \\
\hline Condenser duty $(\mathrm{kW})$ & 16,755 & \\
Reboiler duty $(\mathrm{kW})$ & 18,224 & \\
Pressure (atm) & 1 & 1 \\
Compressor power $(\mathrm{kW})$ & - & 1,794 \\
Reboiler saving $(\%)$ & 0 & 62 \\
\hline \hline
\end{tabular}

Based on MVR technology, the heats of the overheads in two distillation columns are recovered by compressors and exchanged with the heat of bottom stream of the first column. As a result, a dramatic increase in the required energy of the whole process is obtained because of the first column required energy two times more than the second column. The simulation results showed the proposed sequence can save reboiler energy up to $62 \%$ compared to the conventional extractive distillation sequence. It indicates that the proposed sequence is very promising for an azeotropic distillation process.
Additionally, to follow the integrated design perfectly, two additional compressors are required instead of reboilers at the optimal energy point of view. Thus, compared to the conventional process, the capital costs would rise. Nevertheless, when the compressors apply a pressure difference between the inlet and outlet, gas is naturally transported. Therefore, there is a trade-off between operating costs and capital costs. Furthermore, the operating conditions and the size of these columns were kept same to conventional columns. Therefore it is not necessary to check the mechanical calculations for the column. As maximizing the existing equipment, the investment cost for new hardware is able to minimize.

\section{CONCLUSION}

This work presented an innovative integrated sequence based on MVR for the azeotropic distillation. Simulation on a feed mixture of acetone ( $50 \%$ mole) and methanol (50\% mole) showed that the proposed sequence can save $62 \%$ in terms of energy compared with the conventional extractive distillation. Based on this result, some parametric analyses should be considered for the future work to make clear that the difference when applying MVR whether the process is extractive distillation or not.

\section{ACKNOWLEDGMENT}

The research was supported by the Basic Science Research Program through the National Research Foundation of Korea (NRF) funded by the Ministry of Education, Science and Technology (2012012532).

\section{REFERENCES}

[1] B. Linnhoff, H. Dunford, and R. Smith, "Heat integration of distillation columns into overall processes," Chemical Engineering Science, vol. 38, pp. 175, 1983.

[2] W. L. Luyben, "Comparison of extractive distillation and pressure-swing distillation for acetone-methanol separation," Industrial \& Engineering Chemistry Research, vol. 47, pp 2696-2707, February 2008.

[3] J. P. Knapp and M. F. Doherty, "Thermal integration of homogeneous azeotropic distillation sequences," American Institute of Chemical Engineers Journal, vol. 36, pp. 969-984, 1990.

[4] M. F. Doherty and M. F. Malone, Conceptual Design of Distillation Systems, Chemical Engineering Series, New York: McGraw-Hill, 2001.

[5] J. J. Ibarra- Sánchez and J. G. Segovia-Hernández, "Reducing energy consumption and $\mathrm{CO}_{2}$ emissions in extractive distillation: Part II. Dynamic behavior," Chemical Engineering Research and Design, vol. 88, pp. 135-145, 2010.

[6] R. Gutiérrez-Guerra, J. G. Segovia-Hernández, and S. Hernández , "Reducing energy consumption and $\mathrm{CO}_{2}$ emissions in extractive distillation," Chemical Engineering Research and Design, vol. 87, pp. 145-152, 2009.

[7] S. Widagdo and W. D. Seider, "Azeotropic distillation," American Institute of Chemical Engineers Journal, vol. 42, pp. 96-130, 1996.

[8] C. Bravo-Bravo, J. G. Segovia-Hernández, C. Gutierrez-Antonio, A. Duran, A. Bonilla-Petriciolet, and A. Briones-Ramirez, "Extractive dividing wall column: design and optimization," Industrial \& Engineering Chemistry Research, vol. 49, pp. 3672-3688.

[9] F. Abushwireb, H. Elakrami, and M. Emtir, "Recovery of aromatics from pyrolysis gasoline by conventional and energy-integrated extractive distillation," Computer Aided Process Engineering, pp. 1071-1076. 2007.

[10] S. Arifin and I. L. Chien, "Design and control of an isopropyl alcohol dehydration process via extractive distillation using dimethyl 
sulfoxide as an entrainer," Industrial \& Engineering Chemistry Research, vol. 47 pp. 790-803, 2008.

[11] I. D. Gil, A. M. Uyazán, J. L. Aguilar, G. Rodríguez, and L. A. Caicedo, "Separation of ethanol and water by extractive distillation with salt and solvent as entrainer: process simulation," Brazilian Journal of Chemical Engineering, vol. 25, pp. 207-215, 2008.

[12] I. D. Gil, D. C. Botía, P. Ortiz, and O. F. Sánchez, "Extractive distillation of acetone/methanol mixture using water as entrainer," Industrial \& Engineering Chemistry Research, vol. 48, pp. 4858-4865, 2009.

[13] S. Hernández, "Analysis of energy-efficient complex distillation options to purify bioethanol," Chemical Engineering \& Technology, vol. 31, pp. 597-603, 2008.

[14] M. B Shiflett and A. Yokozeki, "Separation of difluoromethane and pentafluoroethane by extractive distillation using ionic liquid," Chimica oggi - Chemistry Today, vol. 24, pp. 28-30, 2006.

[15] N. V. D. Long, "Optimal retrofit design of extractive distillation to energy efficient thermally coupled distillation scheme," American Institute of Chemical Engineers Journal, vol. 59, pp. 1175-1182, 2013.

[16] A. A. Kiss, S. J. F. Landaeta, C. A. I. Ferreira, "Towards energy efficient distillation technologies - making the right choice," Energy, vol. 47, pp. 531-542, 2012.

[17] N. V. D. Long and M. Y. Lee, "A novel NGL (natural gas liquid) recovery process based on self heat recuperation," Energy, vol. 57, pp. 663-670, 2013.

[18] Y. Kansha, N. Tsuru, C. Fushimi and A. Tsutsumi, "New design methodology based on self heat recuperation for production by azeotropic distillation," Enery Fuels, vol. 24, p. 6099-6102, 2010

[19] C. Enweremadu, A. Waheed, and J. Ojediran, "Parametric study of an ethanol-water distillation column with direct vapour recompression heat pump," Energy for Sustainable Development, vol. 13, pp. 96-105, 2009.

[20] Z. Fonyo and N. Benkö, Comparison of various heat pump assisted distillation configurations," Trans. IChemE, vol. 76, 1998.

[21] O. Annakou and P. Mizsey, "Rigorous investigation of heat pump assisted distillation," Heat Recovery Systems \& CHP, vol. 13, pp. 241-247,1995.

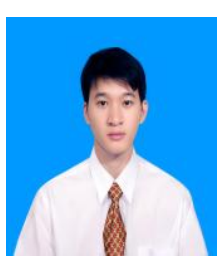

Le Cao Nhien is an MSc student and a research assistant in Process Design and Control Laboratory (PSDC Lab.) at the School of Chemical Engineering, Yeungnam University, South Korea. He received his bachelor degree in chemical engineering from Hochiminh University of Technology in 2011. His research interests are process design, optimization of chemical processes.

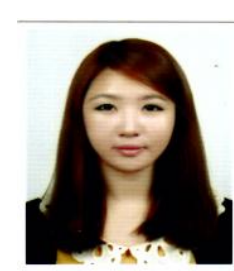

Gyeongmin Kim is an MSc student and research assistant in Process Design and Control Laboratory (PSDC Lab.) at the School of Chemical Engineering, Yeungnam University, South Korea. She received her bachelor degree in chemical engineering from Yeungnam University in 2012. Her research interests are process design, optimization of NGL recovery process.

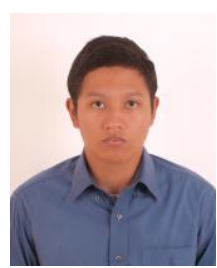

Riezqa Andika is a master student in Process Systems Design and Control Laboratory (PSDC Lab.) at School of Chemical Engineering, Yeungnam University, South Korea. He earned his bachelor degree in 2011 from Universitas Indonesia. Currently he is working on process intensification especially in energy area.

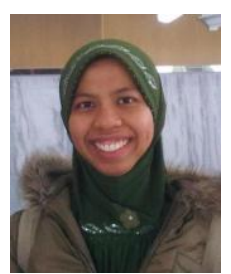

Yuli Amalia Husnil is a $\mathrm{PhD}$ student in Process Design and Control Laboratory (PSDC Lab.) at School of Chemical Engineering, Yeungnam University, South Korea. She completed her master degree in 2009 from University of Indonesia. Her research focus is on energy optimizing control of liquefaction processes.

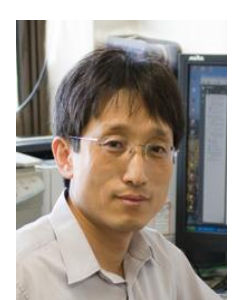

Moonyong Lee is a professor at the School of Chemical Engineering at Yeungnam University in South Korea. He earned his bachelor degree in chemical engineering from Seoul National University, and his master degree and $\mathrm{PhD}$ in chemical engineering from KAIST. He worked in SK energy refinery and petrochemical plants for 10 years as a design and control specialist. His current areas of
specialization include modeling, design and control of 